\title{
Enhancing Physical Education in Omani Basic Education Curriculum: Rationale and Implications
}

\author{
Majida Mehana, Hashem Kilani \\ Sultan Qaboos University, Oman
}

\begin{abstract}
Information on the health status in Oman depicts an increase of non-communicable diseases (NCDs) such as diabetes, overweight, obesity, and metabolic syndrome. An examination of factors related to this increase shows that there is a shift in the daily practices of the people, and especially men, as they grow older towards a more sedentary lifestyle. In addition, school curricula deal with the subject of physical education as a stand-alone topic. Integration of physical activities in the curriculum starting from basic education is warranted if plans to highlight the importance of physical activity and to curb the dramatic increase in NCDs are to succeed. Teachers and health professionals should be competent and aware of health issues affecting the country. Comprehensive programs need to target the child's family and community.
\end{abstract}

\section{Introduction}

Oman is located in the southeastern corner of the Arabian Peninsula and is one of the Gulf countries. The Omani population in 2007 was 1,999.697 and composed as follows: Under 5 (11.58\%), between 5 and less than 15 (24.62\%), between 15 and 49 (56.44\%), between 50 and 59 (3.70\%), and more than 60 years old (3.7\%) [1]. In terms of health profile, Oman has moved from a country dominated by infectious diseases to a country burdened by non communicable diseases (NCDs). In 2005, NCDs accounted for $75 \%$ of the diseases and cardiovascular disease was the leading cause of death. The NCDs were distributed among diabetes (12\%), overweight (30\%), obesity (20\%), high cholesterol (41\%), and metabolic syndrome (21\%) [2]. People living in urban areas were more obese than those living in rural areas. Obesity and overweight combined were more prevalent in the Southern part of Oman. In 1991, more women than men were obese and overweight. The trend was reversed in 2000 with a decrease in the prevalence of overweight and obesity among women and an increase among men [3]. An increase of 6-fold in the elderly population is expected over the next 25 years. Unless attended to, NCDs are a major threat to the country's human and financial resources.
This paper provides an overview of studies that explored the status of health and physical education in Oman. We suggest that a systematic plan of integrating physical education in the curriculum starting with basic education would help in establishing a lifestyle that would decrease the percentage of NCDs. This would also entail the provision of effective teacher preparation programs and targeting the families and communities by providing comprehensive programs.

\section{Health and Physical Education Status}

Many strategies could be tried to curb the expansion of NCDs. These strategies would have to target the lifestyle and behaviors of the population.

A search to locate studies on health and physical education status in Oman revealed that there were very few studies and most were conducted in recent years. The findings reflect an alarming picture. With regards to the health status of Omani children, three studies were found. One study examined the body weight of a cohort of 400 boys and 150 girls in Seeb, Muscat, Oman at 6-7, 12-13, and 15-16 years. A routine health examination was required of all students at entry to primary, preparatory, and secondary levels. The authors computed the Body Mass Index which is weight in kilograms divided by the square of the height in meters at the three ages corresponding to the entry at the three levels. They found that obesity (BMI 30 or above) and overweight (BMI between 25 and 30) combined increased from $7.3 \%$ to $16 \%$ and to $23.3 \%$ at $6-7,12$ 13 , and 15-16 years of age respectively. Obese and overweight children at 6-7 years had a higher risk of maintaining their body weight status at 15-16 years. The longer children retained a normal body weight, the less likely they would be overweight or obese at 15-16 years old [4].

The second study examined heights, weights, maximal oxygen uptake $\left(\mathrm{VO}_{2 \max }\right)$, and activities during leisure time. Two classes were randomly selected from two secondary schools in Muscat, one for girls, and the other for boys. The sample was composed of 83 girls and 64 boys, aged 15-16 years, which corresponded to a participation rate of $85 \%$. Students were asked to fill out a questionnaire detailing their activities during leisure time for the past week. The heights, weights, and maximal 
oxygen uptake $\left(\mathrm{VO}_{2 \max }\right)$ levels were measured. Analyses showed that boys spent more hours on leisure activities than girls. They spent more time engaging in leisure physical activity and on TV viewing, computer games and internet than girls. They also had higher $\mathrm{VO}_{2 \max }$ and lower BMI than girls. It is plausible that the reason for the lesser hours spent by girls in leisure time is that they spend more hours on household chores than boys [5].

The third study involved Grade 3 and 4 boys participating in a summer camp in the Muscat area. They were asked to complete a $1.6 \mathrm{~km}$ run/walk. They also filled out a student and parent questionnaire reporting on the family's lifestyle and health status. A total of 109 boys, equivalent to a response rate of $96 \%$, completed the questionnaire.

Sixty eight percent completed the distance running; the others combined running and walking. Parents reported that children watched TV or played computer/video games for an average of 3.2 hours per day. As for the data on the parents, $32.5 \%$ of the fathers and $8 \%$ of the mothers exercised at least twice weekly. A high father's exercise score was correlated with better child's performance and leanness while mother's obesity had a negative correlation [6].

Children's attitudes towards physical education and actual involvement in activities were the foci of two studies. The first involved newly enrolled students at Sultan Qaboos University (SQU) and the second involved 12 to 15 year-old children enrolled in a summer camp at SQU. The participants in the first study were 352 newly enrolled students at SQU. The study investigated the students' attitudes towards physical activity and their perceived values of six sub domains of physical activity, namely, the social, health, competing, aesthetic, catharsis, and ascetic. Students were selected at random and represented $14 \%$ of accepted students. The findings showed that both males (62\% of the sample) and females (38\% of the sample) exhibited positive attitudes toward physical activity with $91 \%$ engaging in regular weekly physical activity varying from less than two hours to more than 6 hours. Students had highly positive attitudes toward the health sub domain, positive attitudes toward the social, catharsis, aesthetic, and competing sub domains, and slightly unfavorable attitudes toward the ascetic sub domain [7].

The second study involved approximately 50\% of children between 12 and 15 years old participating in the Summer Club at SQU. Results showed that the 147 children held positive attitudes towards physical activity as an avenue to promote health, socialization, and competitiveness. However, this study also found that participants had negative attitudes to the ascetic sub domain of physical activity. They were not comfortable with physical activity as an avenue for adventure. They did not want to take risks that could lead to injuries or involve dangers [8].

At the country level, a total of 2979 students in grades 7 to 10 participated in the 2005 Global School-Based Student Health Survey (GSHS) Results. They answered questions regarding their health and physical practices.

Among the participants in GSHS, 74\% were physically active during the past 7 days for a total of at least 60 minutes per day. The rest were active mostly one or two days of the week. They sat for less than one hour per day (34.2\%), one to two hours per day $(31.4 \%)$, or 3 or more hours per day (34.3\%). They walked or rode a bicycle to school (37\%). Among the students who walked or rode a bicycle to school, 79\% took 29 minutes or less per day [9].

Reviewed studies portray a rough profile of Omani children. They have a positive attitude towards physical activity but don't engage in physical activities for long periods, with girls engaging less than boys.

\section{Interventions}

Preventive measures are needed to address the risk factors associated with NCDs such as inactivity, rising levels in smoking, overweight, and obesity. Physical activity is a main preventive measure as it improves bone health and reduces the risk of developing type 2 diabetes, cardiovascular diseases, and obesity [10].

The Omani government is collecting statistics and providing services to people in all regions. The Ministry of Health is sponsoring many programs that aim to raise awareness regarding NCDs. One such initiative is a community-based intervention in Nizwa, Oman. The Nizwa Healthy Lifestyle Project (NHLP), started in 2004, aims to address the risk factors of NCDs through three subcommittees: tobacco control and accident prevention, promotion of physical activity, and promotion of healthy nutrition. The interventions include identification of NHLP Friendly Schools, implementation of the gulf program Alharaka Baraka (Move for Health) to raise activity in primary schools, lifestyle clinic, obesity screening and management, tobacco intervention, health education in schools and tobacco cessation clinic, and health professionals education and involvement [11].

A study using multistage random sampling was conducted in Nizwa between March and May 2006 to investigate the type and level of physical activity among students. The area is located about $175 \mathrm{~km}$ from the capital, Muscat, and is inhabited by about 70,000 persons. It includes about 77 villages including Nizwa center. The participants were 509 boys and girls between 9 and 20 years old. Eighty percent did not have chronic diseases and $90 \%$ engaged in physical activities. The most common 
activities were walking, running, and playing soccer, with girls mostly walking and running. Girls played at home and at schools while boys played less at home and more at schools, open playgrounds and fields. More than a third of the students were not involved in physical activity at a level that would be enough to prevent a rise of the risk factors at an older age. In adulthood, physical inactivity was about $70 \%$ in females and $50 \%$ in males [12].

Physical activity is influenced by social, behavioral, cultural, and physiological factors. People were inactive for many reasons, namely, lack of awareness of the benefits of physical activity, social values that could restrict women's participation in activities in open spaces, shortage to non-availability of public places for physical activities, and the use of modern life accessories such as cars, TVs, computers, sedentary lifestyles [13]. As a result of the study, the authors recommended using schools to impart information on health and physical fitness, to increase opportunities at schools for children to engage in sports, and to implement the program "Move for Health" for children less than 12 years old in 10 primary schools in Nizwa. Parents are more involved in their children's lives at the formative years. Reaching them and enlisting their cooperation at home to instill healthy habits in children would be effective.

\section{The Basic Education Curriculum}

With the shortage of public places for physical education for boys and girls and scarcity of extra curricular programs, it seems logical as was concluded by the NHLP study to use schools as centers for implementing a solid plan to address risk factors.

Given that the schooling system spans over 12 years, the concepts of a healthy lifestyle throughout the school years could be delivered in a systematic manner. There is no reason to wait for the adulthood period to address the issue with the new generation. The ideal is to start at the basic education level.

According to the National Association for Sport and Physical Education (NASPE), children should accumulate at least 60 minutes of physical activity on all if not most of the days. Periods of activity lasting at least 15 minutes should be spread out throughout the day and include different types of moderate and vigorous activities. The children should be active every couple hours if not earlier. One way to do so is to integrate physical concepts and activities in all subjects [14]. A study in New Zealand gives one example of an initiative to integrate physical activity throughout the subjects and to motivate children to develop habitual physical activity. The study investigated the effect of implementing a 4-week unit that integrates physical education throughout English, social studies, mathematics, and statistics for elementary students aged 8 to 10 years. Children wore pedometers at baseline and throughout the 4 weeks. The average daily step count was computed prior to and during the intervention. Results for 61 children indicated increased daily steps for the least active among boys and girls [15].

Physical education should offer opportunities for competitive sports but more important, it should expose children to a variety of physical activities or sports that could engage children in habitual physical activity throughout life [16].

An examination of the Omani educational system reveals that the first stage of basic education includes Grades 1 to 4 . The subjects include Islamic Education, Arabic, English, Mathematics, Sciences, Social Studies, Physical Education, Artistic Education, Music Education, Environmental Life Skills, and Technology. The total is about 40 periods per week. The subjects are delivered using a variety of teaching methods to meet the needs of diverse learners. There is also integration among certain subjects but physical education is not one of them. It occupies 2 periods per week at each grade level [17].

The Ministry of Education is also implementing an experimental integrative approach in a limited number of schools with a potential for expansion to more schools. Physical Education occupies 3 periods per week (2 hours and 15 minutes) in grades 1 and 2 but it decreases to 2 periods ( 1 hours and 30 minutes) in grades 3 and 4 . The subject remains nonintegrated with other subjects [18].

The allocated time is less than the recommended NASPE guidelines. One justification could be that physical activity is viewed as achieved at the expense of academic performance.

However, many studies that investigated the relationship between school-based physical education/activity and academic performance found encouraging results.

Starting with the preschool years, a review of studies that investigated the environmental factors affecting preschoolers' motor development found that the preschool experience is related to the children's physical activity levels. Developmentally appropriate physical programs, open spaces, and appropriate equipment were related to higher gross motor scores [19]. In addition, organized physical activity such as intervention movement programs can have a positive effect on the acquisition of the performance levels that represent the natural pattern of the skill. In one study, 75 children aged between 5 and 6 years were divided into three groups. Experimental Group A participated in a movement program, experimental Group B participated in a music and movement program where a rhythmic component was added to the movement program, and Group C participated in free play activities as scheduled in the preschool program. Groups A and B 
received instruction from a physical educator twice weekly for 35 minutes each time over a period of 10 weeks. Fundamental locomotor skills under study were running, galloping, hopping, leaping, horizontal jump, and skipping. The skills were measured before and after intervention. Results showed that the skills of the two experimental groups, with or without the rhythmic component, significantly improved their skills in comparison with the control group [20].

At the elementary grade levels, a report summarizing the research on the relationship between academic performance and physical education found that five studies show that allotting more time for physical education did not have any adverse effect on academic performance. Even regular physical activity was an asset to academic performance. Out of 14 studies published between 1967 and 2006, 11 found improved academic performance associated with regular physical activity, two found no relationship between the two, and only one study reported a slightly negative association. Although more research is needed to analyze the mechanisms that relate physical activity to academic performance, activity breaks between classroom lessons increased on-task classroom behavior for elementary students and were even more evident for off-task students [21]. The recommendation for activity breaks between classroom lessons is in concordance with NASPE guidelines [14].

The above studies were reviewed without accounting for the type of design. A comparison between quasi-experimental and cross-sectional studies conducted between 1960 and 2007 confirmed most of the aforementioned results. Two authors researched studies published from 1966 to 2007 via medline, psychinfo, scholar.google.com, and ERIC Databases. They analyzed studies that used quasiexperimental, cross-sectional, and experimental designs. They found that physical education hours could be increased up to an additional hour per day without affecting academic performance. Specifically, six quasi-experimental studies showed that enriched physical education programs did not adversely affect academic performance but in some instances improved it. Ten cross-sectional studies were also reviewed. Physical involvement improved academic achievement in six studies and showed no relationship with academic achievement in two studies. In two studies, physical activity was negatively correlated with academic achievement [22].

Responsive classroom behavior, positive selfesteem, and school satisfaction were positively correlated with increased physical activity levels. However, taking away time from physical education classes did not improve academic achievement and could be associated with development of health risk factors later in life [22].
Inclusion of students with special needs into the regular classroom is on the rise. Intervention programs including physical activity are avenues that could be used for successful inclusion. A review of studies examining the relationship between physical activity and students with special needs showed that different interventions programs were implemented. Results indicated a decrease of behavioral problems in children with attention deficit hyperactivity disorder, an improvement in reading and semantics in children with reading disabilities, and an increased focus on expected tasks in children with emotional and behavioral disorders [22].

\section{Teacher Preparation Programs}

The information on the current health status of Omani children needs to be imparted to university students graduating in physical education and to health professionals in the field through inservice training. Teacher Preparation Programs should include among other things content knowledge about physical education, planning developmentally appropriate units, using teaching methods that involve diverse learners, and assessing physical education and its contributions to the physical, social, cognitive, and emotional domains [23].

\section{Recommendations}

The physical activity level of the Omani child is dependent on the availability of opportunities to engage in such activities. Given the shortage in facilities, schools present the most appropriate medium to reach the highest percentage of the new generation and their families. Starting with basic education is ideal. This suggestion is supported by the fact that around $25 \%$ of the population is between 5 and 15 years old and their parents would be among the $56 \%$ of the population between 15 and 49 years old. Steps are recommended as follows: first, there is a need to analyze the effectiveness and efficiency of the available physical education lessons in basic education; second, to include physical education in an integrative manner in the curriculum wherever possible; third, to combine nutrition, health, and physical information in a meaningful manner; and fourth, to conduct studies on the effectiveness of adding sports components to the curriculum.

Implementing physical education in Omani basic education is by no way a luxury. It is a necessity if the new generation is to adopt a physically active lifestyle and decrease its odds of developing NCDs.

\section{References}

[1] Department of Health Information and Statistics, Health Facts 2007, Directorate General of Planning, 
Ministry of Health, Sultanate of Oman. http://www.moh.gov.om/stat/moh_fact_sheet.pdf. Accessed July 8, 2009.

[2] J. A. Al-Lawati, R. Marby, and A.J. Mohammed, "Addressing the Threat of Chronic Diseases in Oman", Preventing Chronic Disease: Public Health Research, Practice, and Policy, Centers for Disease Control and Prevention, USA, 2008, 5(3), 1-7.

[3] J. A. Al-Lawati and Jousilahti, P.J., "Prevalence and 10-Year Secular Trend of Obesity in Oman", Saudi Medical Journal, Saudi Arabia, 2004, 25(3), 346-51.

[4] Y. F. Osman, S. K. Muscati, S. S. Ganguly, M. Khan, and B. Al-Sharji, "Progression of Obesity among Seeb Children in Oman. A Preliminary Study", Saudi Medical Journal, Saudi Arabia, 2004 Dec, 25(12), 2038-40.

[5] S. Al Barwani, M. Al Abri, K. Al Hashmi, M. Al Shukeiry, K. Tahlilkar, T. Al Zubeidi, O. Al Rawas, and M.O. Hassan, "Assessment of Aerobic Fitness and its Correlates in Omani Adolescents Using the 20-Metre Shuttle Run Test: A Pilot Study", Medical Sciences, Sultan Qaboos University, Oman, 2001, 3(2), 77-80.

[6] M. O. Hassan, and W. Al-Kharusy, "Physical Fitness and Fatness among Omani Schoolboys: A Pilot Study", Medical Sciences, Sultan Qaboos University, Oman, 2000, 2, 37-41.

[7] K. N. Zayed, M. M. Jebali, and A. H. Shoeili, "Attitudes of SQU Students Towards Physical Activity and its Relationships with some Variables", A Series of Psychological and Educational Studies, College of Education, Sultan Qaboos University, Oman, 2004, 48- 77.

[8] K. N. Zayed, A. Hassan, and S. A. Siddiq, "Attitudes of a Sample of Omani Children (12-15 years) towards Physical Activity", Journal of the Service Center for Research Consulting, Faculty of Arts, Menoufiya University, Egypt, 2005, January, 1-20. (Article in Arabic)

[9] World Health Organization, "2005 Global-Based Health Student Health Survey Results: Oman Survey", Global School-Bases Student Health Survey. http://www.who.int/chp/gshs/OMH2005_public_use_code book.pdf. Accessed July 11, 2009.

[10] Department of Health, Physical Activity, Health Improvement, and Prevention. At Least Five a Week. Evidence on the Impact of Physical Activity and Its Relationship to Health. Department of Health, Physical Activity, Health Improvement, and Prevention, London, 2004.

[11] I. Fadhil, "NCD Burden: The Regional Responses". Paper presented at the ECOSOC/UNESCWA/WHO Western Asia Ministerial Meeting "Addressing non communicable diseases and injuries: Major challenges to sustainable development in the $21^{\text {st }}$ century", Qatar, 2009, May 10-11. http://www.un.org/ecosoc/newfunct/pdf/ Doha.P2d.ppt. Accessed July 13, 2009.

[12] A.M. Belal, R.Z. Al Salmi, and Z.A. Al Anqoudi, "The level of Physical Activity among Omani School Children". Paper presented at the First Gulf Conference for
School Children and Adolescent Nutrition, Bahrain, 2006, Nov. 28-30.

http://www.bibalex.org/supercourse/supercourseppt/32011 -33001/32691.ppt (Presentation in Arabic). Accessed July 12, 2009.

[13] A.M. Belal, "Nizwa Healthy Lifestyle Project, Planning, and Implementation Experience 1999-2008", n.d., http://www.bibalex.org/supercourse/ supercourseppt/ 32011-33001/32671.ppt. Accessed July 12, 2009.

[14] National Association for Sport and Physical Education, "Physical Activity for Children: A Statement of Guidelines for Children Ages 5-12", $2^{\text {nd }}$ ed., NASPE, USA, 2004. http://www.aahperd.org/naspe/template.cfm? template=ns_children.html. Accessed June 8, 2009.

[15] M. Oliver, G. Schofield, and E. McEvoy, "An Integrated Curriculum Approach to Increasing Habitual Physical Activity in Children: A Feasibility Study", Journal of School Health, American School Health Association, USA, 2006, 76(2), 74-79.

[16] F. Trudeau and R. J. Shephard, "Is there a Long-Term Legacy of Required Physical Education?", Sports Medicine, 2008, 38(4), 265-70.

[17] Ministry of Education, Sultanate of Oman, "Basic Education: Educational and Administrative Support", Oman Educational Portal, Oman. http://www.moe.gov.om/portal/sitebuilder/sites/EPS/Engli sh/MOE/BasicEducation.aspx. Accessed July 8, 2009.

[18] Ministry of Education, Sultanate of Oman, "Integrative Approach", Oman Educational Portal, Oman. http://www.moe.gov.om/Portal/sitebuilder/Sites/EPS/Engli sh/MOE//integrative\%20approach.aspx. Accessed July 8, 2009.

[19] F. Venetsanou, and A. Kambas. "Environmental Factors Affecting Preschoolers' Motor Development", Early Childhood Education Journal, Springer, Netherlands, 2010, 37(4), 319-327.

[20] E. Deli, I. Bakle, and E. Zachopoulou, "Implementing Intervention Movement Programs for Kindergarten Children", Journal of Early Childhood Research, 2006, 4(1), 5-18.

[21] S. G. Trost, "Active Education: Physical Education, Physical Activity, and Academic Performance", 2007 Fall. http://www.activelivingresearch.org/files/Active_Ed.pdf. Accessed December 24, 2009.

[22] F. Trudeau and R.J. Shephard, "Physical Education and School Physical Activity and School Sports and Academic Performance", International Journal of Behavioral Nutrition and Physical Activity, BioMed Central, 2008, Feb. 25, 5(10), 12 pages. http://www.ijbnpa.org/content/5/1/10. Accessed July 11, 2009.

[23] National Association for Sport and Physical Education, "The National Standards for Beginning 
International Journal for Cross-Disciplinary Subjects in Education (IJCDSE), Volume 1, Issue 2, June 2010

Physical Education Teachers", $2^{\text {nd }}$ ed., NASPE, USA, 2009. http://www.aapherd.org/naspe/

template.cfm?template=ns_beginning.html. Accessed June

8, 2009. 